\title{
Anti-CD11d Integrin Antibody Treatment Restores Normal Serotonergic Projections to the Dorsal, Intermediate, and Ventral Horns of the Injured Spinal Cord
}

\author{
Mark A. Oatway, ${ }^{1,2}$ Yuhua Chen, ${ }^{1}$ Jamie C. Bruce, ${ }^{1}$ Gregory A. Dekaban, ${ }^{1,2}$ and Lynne C. Weaver ${ }^{1,2}$ \\ ${ }^{1}$ BioTherapeutics Research Group, Robarts Research Institute, and ${ }^{2}$ The Graduate Program in Neuroscience, The University of Western Ontario, London, \\ Ontario, N6A 5K8, Canada
}

\begin{abstract}
Spinal serotonergic pathways provide inhibitory and excitatory modulation of sensory, autonomic, and motor processing. After spinal cord injury (SCI), the acute inflammatory response is one process that damages descending pathways. Increases in serotonergic fiber density in spinal segments rostral and decreases caudal to the lesion have been observed previously and may contribute to neuropathic pain and motor dysfunction associated with SCI. We investigated the effect of an acute anti-inflammatory treatment on the density of serotonergic fibers rostral and caudal to a thoracic SCI lesion. This treatment, a monoclonal antibody to the CD11d subunit of the leukocyte CD11d/CD18 integrin, limits the trafficking of neutrophils and macrophages into the SCI site. In the dorsal horn, after treatment, the typically increased serotonin immunoreactivity rostral to injury was reduced, whereas that caudal to the lesion increased toward normal. Coincidently, mechanical allodynia in the dorsal trunk and hindpaws was significantly reduced. Increased serotonergic fiber density below the lesion also occurred in the intermediolateral cell column and ventral horn of treated rats, relative to controls. Improved locomotor recovery paralleled this increased serotonin. The treatment increased compact myelin in and near the lesion epicenter and increased serotonergic fiber bundles coursing around part of the lesion but had no consistent effect on the number of raphe-spinal neurons retrogradely labeled by tracer injection below the injury. In conclusion, this anti-CD11d integrin antibody treatment is neuroprotective after SCI, corresponding with improved patterns of intraspinal serotonergic innervation. The improvement in serotonergic fiber projections paralleled reduced mechanical allodynia and enhanced locomotor recovery.
\end{abstract}

Key words: serotonin; spinal; pain; movement; dorsal horn; intermediolateral; motoneuron; inflammation; integrin; myelin; injury

\section{Introduction}

Spinal cord injury (SCI) leads to loss of descending serotonergic [5-hydroxytryptamine (5-HT)] control of several populations of spinal neurons. Spinal serotonergic projections from the nucleus raphe magnus (NRM) synapse in the dorsal horn, causing inhibition or facilitation of pain signaling that depends on the receptor that is stimulated (Calejesan et al., 1998; Bardin et al., 2000). Serotonergic neurons within the nuclei raphe obscurus and pallidus target sympathetic preganglionic neurons in the intermediolateral cell column (IML), contributing to autonomic regulation (Allen and Cechetto, 1994; Jacobs et al., 2002). Descending serotonergic axons also provide excitatory input to ventral horn $\alpha$-motoneurons (Saruhashi et al., 1996). Thus, loss of descending serotonergic inputs caudal to the lesion site contributes to neu-

Received Sept. 23, 2004; revised Nov. 29, 2004; accepted Nov. 29, 2004.

This work was supported by grants from the Ontario Neurotrauma Foundation and the Heart and Stroke Foundation of Ontario (T4503). M.A.0. was supported by a Studentship Award from the Ontario Neurotrauma Foundation. We are grateful to the ICOS Corporation for supplying the anti-CD11d mAb antibody used in this study. We are indebted to Sunil John for technical assistance with the studies and to Dr. Canio Polosa for his critical evaluation of this manuscript.

Correspondence should be addressed to Dr. Lynne C. Weaver, The Spinal Cord Injury Team, BioTherapeutic Research Group, Robarts Research Institute, P.0. Box 5015, 100 Perth Drive, London, Ontario, N6A 5K8, Canada. E-mail: Icweaver@robarts.ca.

DOI:10.1523/JNEUROSCI.3960-04.2005

Copyright $\odot 2005$ Society for Neuroscience $\quad$ 0270-6474/05/250637-11\$15.00/0 ropathic pain and motor dysfunction after SCI (Saruhashi et al., 1996; Hains et al., 2002) and, potentially, to autonomic dysfunction.

In addition to loss of serotonergic axons below the lesion level, a marked increase in the area of serotonergic immunoreactivity (5-HT-IR) occurs in the dorsal horn of spinal segments immediately rostral to the injury (Bruce et al., 2002; Inman and Steward, 2003). These segments correspond with dermatomes in which a band of mechanical allodynia often develops (Tasker, 1990; Vierck et al., 2000). This at-level pain can be attributed to the increased serotonin because it is blocked by the $5-\mathrm{HT}_{3}$ receptor antagonist ondansetron (Oatway et al., 2004). In contrast, neuropathic pain caudal to an SCI can be caused by loss of serotonergic actions on $5-\mathrm{HT}_{1}$ and $5-\mathrm{HT}_{2}$ receptors (Hamon and Bourgoin, 1999; Hains et al., 2002). Therefore, both plasticity of descending serotonergic fibers above an injury and their loss below the injury contribute to neuropathic pain after SCI.

The severity of an injury depends, in part, on secondary events that include inflammation and oxidative damage (Bethea and Dietrich, 2002). During the early inflammation, neutrophils and monocyte/macrophages infiltrate the lesion, releasing proinflammatory cytokines and chemokines and generating free radicals, ultimately resulting in secondary tissue necrosis and scar formation (Popovich et al., 1999; Plunkett et al., 2001). We have 
shown that an early anti-inflammatory treatment (Mabon et al., 2000; Saville et al., 2004) enhances motor and autonomic recovery and also decreases mechanical allodynia both at and below the level of the lesion (Gris et al., 2004). This treatment, a monoclonal antibody (mAb) to the CD11d subunit of the leukocyte CD11d/CD18 integrin, blocks leukocyte infiltration through the blood-CNS barrier, reducing neutrophil and macrophage numbers at the lesion site (Saville et al., 2004). We speculated that this treatment decreased chronic pain and improved motor and autonomic function, in part, by preventing the respective increases and decreases in serotonergic input to neurons rostral and caudal to a moderate SCI. To test this hypothesis, we assessed the density and distribution of 5-HT-immunoreactive fibers in the dorsal, intermediate, and ventral horns in sham-injured, vehicle-treated, and anti-CD11d mAb-treated rats. Retrograde tracing was used to determine the raphe-spinal connections caudal to the injury, and areas of spared compact myelin were determined. Changes in at-level and below-level mechanical allodynia and in motor performance were also evaluated.

\section{Materials and Methods \\ Surgical procedures and treatment paradigm}

All experimental procedures were approved by the University of Western Ontario Animal Care Committee in accordance with the Canadian Guide to Care and Use of Experimental Animals. Forty-seven male Wistar rats (Charles River, Ontario, Canada) weighing 220-350 g were housed individually. Before surgery, animals were medicated with diazepam (3.5 $\mathrm{mg} / \mathrm{kg}$, i.p.; Sabex International, Boucherville, Quebec, Canada) and atropine $(0.05 \mathrm{mg} / \mathrm{kg}$, s.c.; Sigma, St. Louis, MO) as described previously (Weaver et al., 2001) and anesthetized with 2.0\% halothane.

A dorsal laminectomy was performed, removing the dorsal processes of the 10th and 11th thoracic vertebrae and exposing the 12th-13th thoracic spinal cord segments. Using a modified aneurysm clip calibrated to generate a force of $35 \mathrm{~g}$, the cord was compressed dorsoventrally for $60 \mathrm{~s}$ in 41 rats. This calibrated force produces a "moderate" SCI. We have previously characterized the pathology and functional recovery of a moderate injury in comparison with severe injury (Bruce et al., 2002; Gris et al., 2004). Care was taken to place the clip around the cord without disrupting the dura mater or adjacent dorsal roots. In animals receiving sham injury $(n=6)$, the dorsal processes of the 10th and 11th thoracic vertebrae were removed without exposing the spinal cord. The muscle and skin were closed in layers, and the animals recovered under a heat lamp. Postoperative care was provided using antibiotics administered subcutaneously (Baytril, $50 \mathrm{mg} / \mathrm{ml}$; Bayer, Toronto, Ontario, Canada) and $5 \mathrm{ml}$ of subcutaneous $0.9 \%$ normal saline twice daily for $3 \mathrm{~d}$. The animals were housed on extra bedding to prevent the development of pressure and friction sores. Urinary bladders were manually emptied by abdominal compression twice daily until spontaneous voiding returned in $7-10 \mathrm{~d}$.

After surgery, the rats were blindly assigned to one of two treatment groups. The treated group $(n=19)$ received the anti-CD11d mAb $(1.0$ $\mathrm{mg} / \mathrm{kg}$; gift from the ICOS Corporation, Bothell, WA), whereas a second, vehicle-treated control group received equivalent volumes of $0.9 \%$ normal saline $(n=22)$. The treated rats received the antibody or saline at 2 , 24 , and $48 \mathrm{~h}$ after SCI, intravenously via the tail vein.

\section{Retrograde labeling of neurons in the raphe nuclei}

The retrograde tracing method used to label cell bodies within the raphe nucleus has been described previously (Fehlings and Tator, 1995; Joshi and Fehlings, 2002). Three weeks after the clip-compression injury, a laminectomy was performed caudal to the original spinal injury site, removing the dorsal process of the third lumbar vertebra. Using a \#11 scalpel blade, the dura and cord were transected at the fourth lumbar segment. Microscissors were used to eliminate any residual tissue connection at the transection site. A $3 \times 3 \mathrm{~mm}$ Gelfoam pledget (Amersham Biosciences, Mississauga, Ontario, Canada) was used to absorb $7.5 \mu \mathrm{l}$ of $4 \%$ Fluorogold (hydroxystilbamidine; Fluorochrome, Englewood, CO).
Once bleeding was controlled, the Gelfoam pledget was placed at the transection site against the proximal stump of the cord. Dispersion of the Fluorogold was minimized by applying petroleum jelly over the transection site. The rats survived for $7 \mathrm{~d}$ after transection to allow the tracer to be transported to the medulla. To ensure that the Fluorogold traveled through the lesion site and to the medulla via retrograde axonal transport and not by passive dispersion through the CSF, a control injury was used in which the cord was transected at the junction of the 12th and 13th thoracic segments rather than compressed $(n=3)$. The tracer was then applied at the fourth lumbar segment as described previously.

\section{Tissue preparation and processing}

Perfusion of rats. One month after surgery, all rats were deeply anesthetized with urethane $(2.5 \mathrm{~g} / \mathrm{kg}$, i.p; Sigma) and perfused as described previously (Bruce et al., 2002). Tissue used for 5-HT processing (T9-11 and L2-4 sections) was cut with a cryostat into $30 \mu \mathrm{m}$ transverse sections. Longitudinal serial sections of the lesion area for 5-HT processing were cut at $25 \mu \mathrm{m}$ and thaw-mounted on gelatin-coated slides. Tissue used for lesion assessment (T12-L1 scar) was serially sectioned at $20 \mu \mathrm{m}$ in the transverse plane and thaw-mounted onto slides. The brainstem was removed using sterotaxic coordinates as described previously (Paxinos and Watson, 1986). Using a \#11 scalpel blade, dorsoventral cuts were made using the corticocerebellar junction as a rostral reference and the sixth cerebellar lobule as a caudal axis reference. The brainstem was cut with a cryostat into $30 \mu \mathrm{m}$ transverse sections and serially mounted onto slides.

Lesion myelin assessment. Serial sections of tissue encompassing the lesion epicenter and areas $2.8 \mathrm{~mm}$ rostral and caudal were stained with Luxol fast blue dye (Ainge et al., 1969). This permitted identification of tightly packed, nondegraded myelin and provided an assessment of the lesion site integrity and cavitation spread in the rostral and caudal directions.

Immunohistochemistry. Floating transverse sections of spinal cord were blocked for $60 \mathrm{~min}$ in Tris PBS plus $0.3 \%$ Triton X-100 (TPBS-X) containing $10 \%$ normal goat serum (NGS). Sections were then incubated for $72 \mathrm{~h}$ in a 1:20,000 dilution of a rabbit anti-5-HT polyclonal antibody (Diasorin, Stillwater, MN) in TPBS-X containing 1\% NGS. The tissue was then incubated in a 1:250 dilution of biotin-conjugated goat antirabbit antibody (Jackson ImmunoResearch, West Grove, PA) for $12 \mathrm{~h}$ followed by extravidin-peroxidase for $4 \mathrm{~h}$, and immunoreactivity was revealed using nickel-enhanced diaminobenzidine. Several sections were processed without the primary antibody incubation step to verify a lack of nonspecific staining.

Longitudinal sections of the lesion area and of the brainstem were processed on slides, and serotonin was detected by immunofluorescence. After the $72 \mathrm{~h}$ incubation with the rabbit anti-5-HT primary antibody, sections were processed with biotin-conjugated goat anti-rabbit (1:400) for $12 \mathrm{~h}$ and incubated for $4 \mathrm{~h}$ in a 1:200 dilution of rhodamine-lissamine conjugated to streptavidin (Jackson ImmunoResearch). To control for nonspecific secondary antibody labeling, the 5-HT primary antibody was preincubated overnight with its corresponding antigen (5-HT, $1.0 \mathrm{mg} /$ $\mathrm{ml}$; Sigma) at $4^{\circ} \mathrm{C}$ and then applied to the tissue instead of the primary antiserum. No signal was detected in the tissue when this preincubated antibody was used.

\section{Density and distribution assessment of spinal \\ serotonergic immunoreactivity}

Randomly selected floating, transverse sections (T9-11, L2-L4) were mounted on slides and viewed. Immunoreactivity was viewed by light and fluorescence microscopy using a Leica microscope (Leica, Richmond Hill, Ontario, Canada). Digitized images, captured using a DAGE video camera (MTI, Michigan City, IN) for bright-field images and a Retiga 1300 camera (Q Imaging, Burnaby, British Columbia, Canada) for fluorescent images, were collected and processed using Image Pro Plus software (Media Cybernetics, Silver Spring, MD). Image processing software was used to normalize all images to a common pixel intensity range, providing an equalized comparison as described previously (Bruce et al., 2002). The pixel size was $0.8 \times 1.0 \mu \mathrm{m}^{2}$, ensuring that areas of immunoreactivity would reflect both changes in numbers of fibers containing reaction product and greater amounts of reaction product in a fiber. 
Quantification of the dorsal horn 5-HT-IR was performed by visually selecting an area of interest encompassing laminas I-IV for each individual image. The total area of interest was $136 \mathrm{~mm}^{2}$ for sections within the T9-11 segment and $272 \mathrm{~mm}^{2}$ for L2-4 sections. For each segment, $20-25$ sections per animal were quantified by randomly selecting one section per row of 8 on a slide. A similar selection procedure was used to quantify the projections to sympathetic preganglionic neurons in the IML rostral and caudal to the injury, as well as projections to motor neurons in the ventral horn caudal to the injury. The total area of interest quantified for the IML in T9-11 and L2-4 sections was $208 \mathrm{~mm}^{2}$. Similarly, a total area of $290 \mathrm{~mm}^{2}$ was quantified to assess the ventral horn within the L2-4 segment. The ventral horn area of interest encompassed laminas VII-IX, and care was taken to exclude any fibers from the IML to avoid redundant quantification.

Areas of serotonergic fibers were assessed in longitudinal sections of the lesion contained within one low-power $(4 \times)$ field. This area was bordered rostrally by the abrupt border between normal and damaged tissue characteristic of the compression injury model, often including the rostral border of a cystic cavity (Weaver et al., 2001). The area of interest included the full width of the spinal cord and was $5.0 \pm 0.03 \mathrm{~mm}^{2}$ per section in saline-treated rats and $4.5 \pm 0.8 \mathrm{~mm}^{2}$ per section in antiCD11d mAb-treated rats. These areas of interest were not significantly different from each other. Approximately 12 sections of the lesion progressing from dorsal to ventral planes through the cord were analyzed in each rat.

\section{Assessment of compact myelin sparing}

At 4 weeks after SCI, the rats were perfused with $4 \%$ formaldehyde, and the spinal cord was removed, cryostat-sectioned transversely at $20 \mu \mathrm{m}$, and serially thaw-mounted on alternate slides. Sections were processed using Luxol fast blue staining to identify tightly packed myelin. Digitized images of every eighth section on a slide were captured in serial order from $2.8 \mathrm{~mm}$ rostral to $2.8 \mathrm{~mm}$ caudal to the epicenter of the lesion, and the stained area was quantified using a calibrated analysis program of Image Pro Plus software (Media Cybernetics). An area of interest encompassing the entire circumference of the transverse section was selected. The area measurements were normalized for analysis because of the distortion of the overall cord area by a large cystic cavity at and near the lesion in some rats. We first established that the cord cross-sectional area within a length $3 \mathrm{~mm}$ rostral and caudal to the T12 dorsal roots is uniform in the normal intact spinal cord. Areas of staining were then expressed in each rat as a percentage of the total cross-sectional area of the relatively intact thoracic cord sampled 3-4 $\mathrm{mm}$ rostral to the epicenter of the injury. These standard areas used for normalization were similar in control $\left(4.0 \pm 0.3 \mathrm{~mm}^{2}\right)$ rats and in anti-Cd11 d mAb-treated rats $(3.6 \pm$ $\left.0.2 \mathrm{~mm}^{2}\right)$. The averaged area of five sections was calculated and plotted as a sample at $0.4 \mathrm{~mm}$ lengths along the cord. The smallest average area was considered the epicenter of the lesion.

\section{Counts of retrogradely labeled neurons in the raphe nuclei}

Fluorogold-positive neurons within the nucleus raphe magnus and the nucleus raphe pallidus were visualized using an Olympus BX50 microscope with a UV filter $(330-380 \mathrm{~nm})$. Every section was photographed ensuring the same area of interest by using the basilar artery and the pyramidal tracts as a ventral landmark. After all Fluorogold-labeled images were captured, random sections were selected and stained using Gill \#3 hematoxylin solution (Sigma) to verify medullary nuclear morphology. Immunocytochemical detection of 5-HT in the Fluorogold-labeled cells also confirmed that many of the raphe-spinal neurons were serotonergic.

Counting of labeled cells was performed using an unbiased stereological procedure (Gundersen et al., 1988). A variation of the physical disector (Sterio, 1984) was used to count labeled cell bodies using three reference slides. Profiles to be counted were identified in a middle section, termed the reference section, and were compared with the preceding adjacent section, the look-up section. Profiles that were present in the reference section but not present in the look-up section were counted. A $200 \times 200 \mu \mathrm{m}$ square grid was applied over each section allowing a direct quadrant-to-quadrant comparison between images. Only profiles that appeared as clear cell bodies were counted; profiles appearing to be soma fragments or dendrites were excluded from the counts. To facilitate the identification of intact cellular morphology, the contrast of each image was inverted within the analysis program, allowing visualization of black cell bodies on a white background. To quantify a similar medullary area in each, a rostrocaudal border was established and defined as being the initial $1260 \mu \mathrm{m}$ from the caudal axis of the raphe nucleus (Reid et al., $1975)$. With this measurement, 42 sections were quantified for each animal ( $n=5$ anti-CD11d treated; $n=6$ saline treated). The investigator performing the cell quantification was blinded to the treatment groups.

\section{Behavioral procedures}

At-level mechanical allodynia. The development of mechanical allodynia immediately rostral to and at the level of SCI lesion was tested on the dorsal surface of the trunk as described previously (Bruce et al., 2002; Oatway et al., 2004). At-level segmental pain is defined as occurring at the transitional zone between normal sensation and sensory loss, generally within a band of two to four spinal segments rostral to the lesion site (Siddall and Loeser, 2001). Briefly, a modified Semmes-Weinstein filament calibrated to generate an innocuous force of $15 \mathrm{mN}$ was used to stimulate the dermatome areas corresponding to the 9th-11th thoracic spinal segments. The skin area corresponding to dermatomes of the 12th and 13th segments (the field of surgery) was avoided. Rats were acclimated to a Plexiglas box for $20 \mathrm{~min}$ and then stimulated 10 times at random points within the dorsal trunk area. Each stimulus lasted $3 \mathrm{~s}$ and was separated by a $5 \mathrm{~s}$ interim period. The number of avoidance responses elicited from 10 stimulations was then tabulated. Testing resumed $7 \mathrm{~d}$ after injury, with two testing sessions per week for the subsequent 4 weeks after injury. As described previously (Bruce et al., 2002; Oatway et al., 2004), pain testing was done only in animals with sufficient motor recovery to execute a voluntary avoidance response. This corresponds to an approximate Basso, Beattie, and Bresnahan (BBB) score of six points. Avoidance responses were defined as flinching, escape, paw withdrawal and/or licking, vocalization, or abnormal aggressive behavior.

Below-level mechanical allodynia. The development of mechanical allodynia below the level of SCI was tested on the plantar surface of the hindpaw. Before SCI, rats were acclimated to a Plexiglas chamber $(8 \times$ $3.5 \times 3.5$ inches) consisting of plastic, mesh walls and an elevated, mesh floor. Similar to dorsal trunk testing, a testing session consisted of 10 stimulations to the plantar surface of the hindpaw. Avoidance responses were defined as described above. After the testing of one hindpaw, a 2 min interim period lapsed before the second hindpaw was tested. The number of withdrawal responses for each hindpaw was tabulated, and the mean number of withdrawals within both hindpaws was calculated. Testing resumed $7 \mathrm{~d}$ after injury with two paw-testing sessions per week for the subsequent 4 weeks after injury. These testing sessions occurred on alternate days, ensuring that no animal was tested twice on the same day.

Locomotor function. Hindlimb locomotor recovery was observed and recorded by two blinded observers using the $\mathrm{BBB}$ locomotor rating scale (Basso et al., 1995). Assessment commenced at $5 \mathrm{~d}$ after injury and continued twice per week for the subsequent 4 weeks after injury.

\section{Statistical analysis}

In assessing differences in the area of 5-HT-IR, a completely randomized ANOVA was performed followed by a Fisher's protected $t$ test (Sokol and Rohlf, 1981). This parametric test was used for comparisons among sham-injured, control-injured, and treated cord-injured groups. Values are represented as mean area of immunoreactivity (square micrometers) \pm SE. Statistically significant differences were accepted at $p<0.05$. Areas of 5-HT immunoreactivity in longitudinal sections of the spinal cord lesion were compared using a two-sample Student's $t$ test. Differences between the treated and control groups in the raphe nucleus cell counts also were determined by a two-sample Student's $t$ test. A variance stabilizing square root transformation was performed on raw counts of labeled neurons before statistical analysis because of the large variance within groups. Treatment effects on variance in these two groups were analyzed by a Fischer $F$ ratio test (Sokol and Rohlf, 1981). Data are presented as mean transformed numbers of labeled cells \pm SE. 

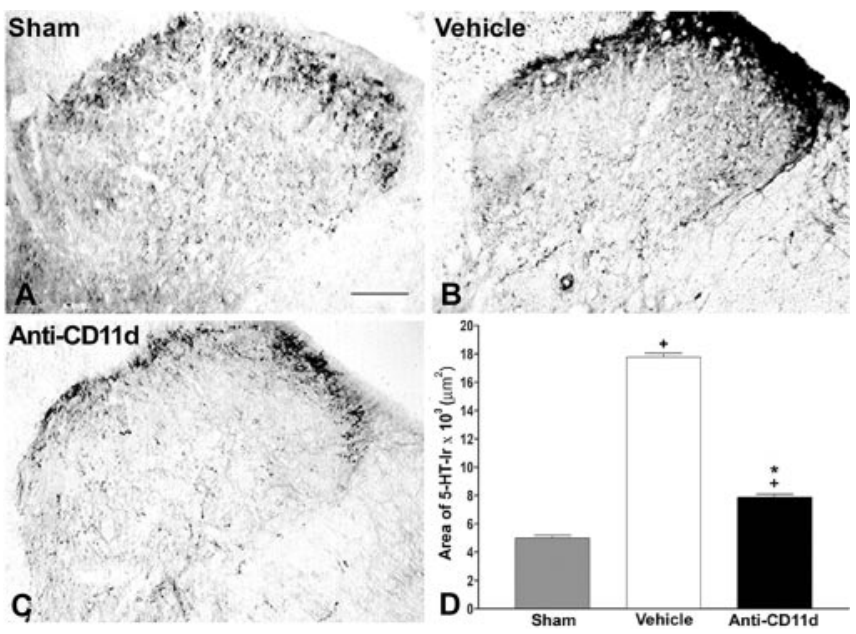

Figure 1. 5-HT-IR in laminas I-IV of the dorsal horn rostral to injury 4 weeks after SCI. Photomicrographs of transverse sections of the dorsal horn in sham-injured, vehicle-treated, and anti-CD11d mAb-treated animals. After SCl, the distribution and density of 5-HTimmunoreactive fibers were increased significantly, primarily in the superficial laminas, with punctate fibers in laminas III and IV. Anti-CD11d mAb treatment normalized the distribution of 5-HT-immunoreactive fibers toward patterns observed in sham-injured animals. Scale bar, 100 $\mu \mathrm{m}$. The area of 5-HT-IR in the dorsal horn rostral to the injury at T12-13 represented the mean area \pm SE of 5-HT-IR in the sham injured $(n=6)$, vehicle-treated $(n=5)$, and anti-CD11d mAb-treated $(n=6)$ groups. ${ }^{*} p<0.05$ compared with vehicle-treated rats; ${ }^{+} p<0.05$ compared with sham-injured rats.

In assessments of mechanical allodynia, all values are represented as mean number of avoidance/withdrawal responses to 10 stimulations \pm SE. Quantitative results regarding the development of mechanical allodynia during the initial 4 weeks after injury were subjected to a repeated measures ANOVA. A Fisher's protected $t$ test was used to compare differences between the values before and after injury as well as differences between weeks after injury. Similarly, mechanical allodynia and locomotor differences between anti-inflammatory-treated and control-injured groups were determined using a repeated measures ANOVA and a Fisher's protected $t$ test. Locomotor data are displayed as mean BBB score \pm SE. Differences were considered significant when $p<0.05$.

\section{Results}

Anti-CD11d mAb treatment modulates dorsal horn serotonergic fiber density rostral and caudal to lesion

Four weeks after SCI, the distribution and density of 5-HT fibers within laminas I-IV of the dorsal horn were examined both immediately rostral (T9-11) and caudal (L2-4) to the lesion site. The area of 5-HT-IR was compared within three groups: shaminjured, injured with vehicle treatment, and injured with antiCD11d mAb treatment (Fig. 1). Most of the fibers expressing 5-HT-IR were localized within the superficial laminas (I and II) of the rostral and caudal segments in all three groups. Immunoreactivity was less apparent throughout laminas III-IV, particularly within the sham-injured group.

At 4 weeks after surgery, 5-HT-IR within laminas I-IV of sham-injured animals consisted of punctate fibers, primarily within the superficial laminas (Fig. $1 A$ ). In sham-injured rats, the area of 5-HT-IR in laminas I-IV of segments T9-11 was $4984 \pm$ $841 \mu \mathrm{m}^{2}(n=6)$. The area of 5-HT-IR was significantly increased in the rostral segments (T9-11) to $17,761 \pm 1014 \mu \mathrm{m}^{2}$ in the vehicle-treated SCI group $(n=5 ; p<0.05)$. This approximately fourfold increase was most apparent within the superficial laminas and was accompanied by an increased number of fibers spread throughout laminas III and IV (Fig. $1 B$ ). After antiCD11d mAb treatment, 5-HT fiber distribution in T9-11 ap-
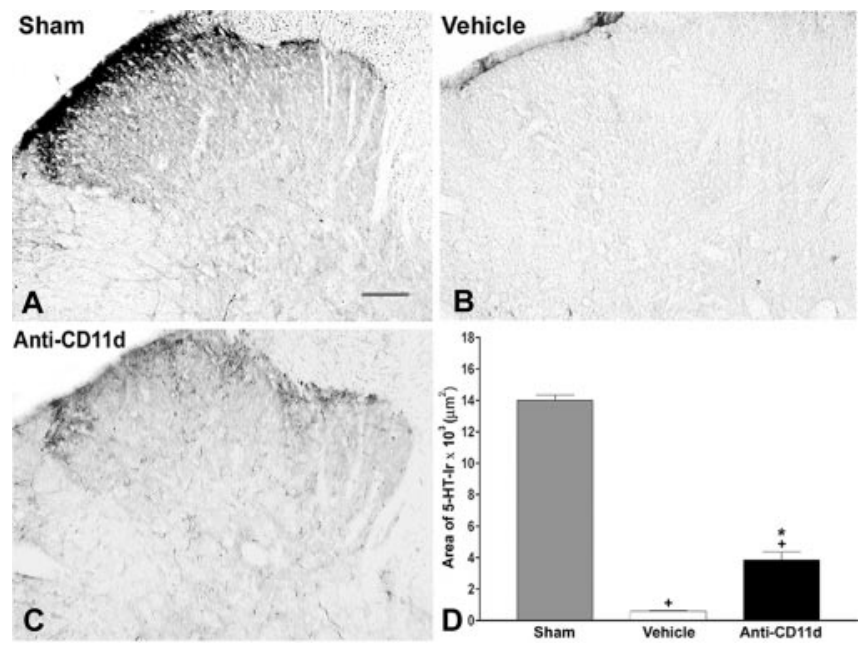

Figure 2. 5-HT-IR in laminas I-IV of the dorsal horn caudal to injury 4 weeks after SCI. Photomicrographs of transverse sections of the dorsal horn in sham-injured, vehicle-treated, and anti-CD11d mAb-treated animals. After SCl, 5-HT-immunoreactive fibers were completely absent in most dorsal horn sections. 5-HT-immunoreactive fibers were present as tortuous fiber within the superficial laminas after anti-CD11d mAb treatment. Scale bar, $100 \mu \mathrm{m}$. The area of 5 -HT-IR (mean $\pm \mathrm{SE}$ ) in the dorsal horn caudal to the injury at T12-13 is plotted for the sham-injured ( $n=5$ ), vehicle-treated $(n=5)$, and anti-CD11d mAb-treated ( $n=5)$ groups. ${ }^{*} p<0.05$ compared with vehicle-treated rats; ${ }^{+} p<0.05$ compared with sham-injured rats.

peared normalized within the superficial laminas (Fig. $1 C$ ). The area of 5-HT-IR after mAb treatment, $7884 \pm 516 \mu \mathrm{m}^{2}(n=6)$, was significantly less than that in the vehicle-treated group (Fig. $1 D)(p<0.05)$.

The distribution of 5-HT-IR in laminas I-IV of segments caudal to the injury (L2-4) in the sham-injured group was similar to that in T9-11, but expression was more intense (Fig. 2A). The area of 5-HT-IR in laminas I-IV in this group was 14,000 \pm 756 $\mu \mathrm{m}^{2}(n=5)$. In a majority of cases, 5 -HT-IR was completely lost caudal to the SCI in vehicle-treated SCI rats, with the occasional exception of sparsely distributed fibers remaining within the superficial laminas (Fig. 2 B). The area of immunoreactivity in L2-4 was significantly decreased to $589 \pm 159 \mu \mathrm{m}^{2}$ in vehicle-treated animals $(n=5 ; p<0.05)$. After treatment with the anti-CD11d $\mathrm{mAb}$, tortuous, punctate fibers were distributed randomly throughout the superficial laminas (Fig. 2C). In this group of rats, the area of 5-HT-IR in L2-4 (3842 $\left.\pm 1190 \mu \mathrm{m}^{2} ; n=5\right)$ was significantly increased after anti-CD11d mAb treatment when compared with that after vehicle treatment (Fig. $2 D)(p<0.05)$.

\section{Anti-CD11d mAb treatment increases serotonergic fiber distribution in the IML caudal to lesion}

To investigate whether the modulation of 5-HT fiber density and distribution observed in the dorsal horn after anti-CD11d mAb treatment was consistent throughout other laminas within the same segments, the area of 5-HT-IR was quantified in the IML (Fig. 3). In the T9-11 segments of sham-injured animals, 5-HT-IR appeared in long and varicose fibers clustered in the IML and spread medially toward the central canal as well as laterally within the white matter (Fig. 3A). The area of 5-HT-IR in the IML of segments T9-11 in the sham-injured group was $3331 \pm 495 \mu \mathrm{m}^{2}(n=6)$. The areas of immunoreactivity in the segments rostral to the lesion site were not significantly altered after vehicle treatment $\left(3944 \pm 797 \mu \mathrm{m}^{2} ; n=5\right)$ or anti-CD11d mAb treatment $\left(4662 \pm 324 \mu \mathrm{m}^{2} ; n=6\right)$ (Fig. $\left.4 D\right)$. In the vehicle- and mAb-treated groups, the distribution and morphol- 

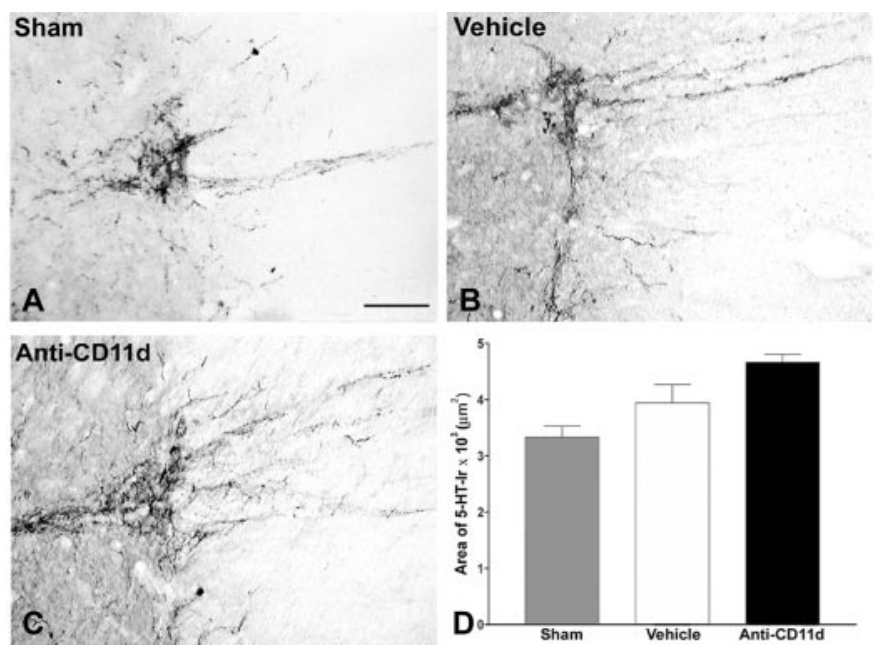

Figure 3. 5-HT-IR in the intermediolateral cell column rostral to injury 4 weeks after $\mathrm{SCl}$. Photomicrographs of transverse sections in the area of the intermediolateral cell column in sham-injured, vehicle-treated, and anti-CD11d mAb-treated animals. AfterSCl, the distribution and density of 5-HT-immunoreactive fibers were similar in all three groups. Scale bar, $50 \mu \mathrm{m}$. The area of 5 -HT-IR (mean $\pm \mathrm{SE}$ ) in the intermediolateral cell column rostral to the injury at T12-13 is plotted for the sham-injured ( $n=6)$, vehicle-treated $(n=5)$, and anti-CD11d $\mathrm{mAb}$-treated $(n=6)$ groups.

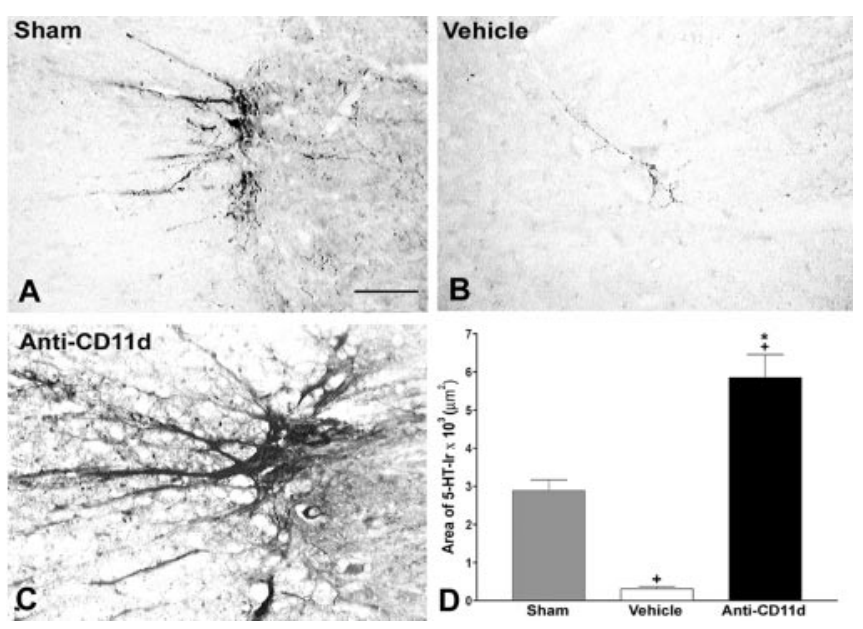

Figure 4. 5-HT-IR in the intermediolateral cell column caudal to injury 4 weeks after SCl. Photomicrographs of transverse sections of the intermediolateral cell column in sham-injured, vehicle-treated, and anti-CD11d mAb-treated animals. After SCl, the varicose, 5-HTimmunoreactive fibers were sparsely distributed within the IML. Anti-CD11d mAb treatment resulted in approximately a twofold increase in 5 -HT-IR characterized by a robust fiber distribution and rounded, somata-like structures. Scale bar, $50 \mu \mathrm{m}$. The area of 5-HT-IR (mean \pm $\mathrm{SE}$ ) in the intermediolateral cell column caudal to the injury at T12-13 is plotted for the shaminjured $(n=6)$, vehicle-treated $(n=5)$, and anti-CD11d mAb-treated $(n=6)$ groups. ${ }^{*} p<$ 0.05 compared with vehicle-treated rats; ${ }^{+} p<0.05$ compared with sham-injured rats.

ogy of 5-HT-immunoreactive fibers were similar to those observed in the sham-injured animals (Fig. $3 B, C$ ).

In segments caudal to the lesion (L2-3), the distribution of 5-HT-immunoreactive fibers in the IML of sham-injured rats was similar to that described for the thoracic segments (Figs. $3 A$, $4 A)$. The area of 5-HT-IR in sham-injured rats was $2891 \pm 683$ $\mu \mathrm{m}^{2}(n=6)$. In contrast, 4 weeks after SCI, 5 -HT-IR at L2-3 was eliminated almost completely in vehicle-treated animals, with the exception of individual varicose fibers evident in some sections (Fig. $4 B$ ). The area of 5-HT-IR was significantly decreased to $310 \pm 125 \mu \mathrm{m}^{2}$ in this group $(n=5 ; p<0.05)$ (Fig. $4 D$ ). After
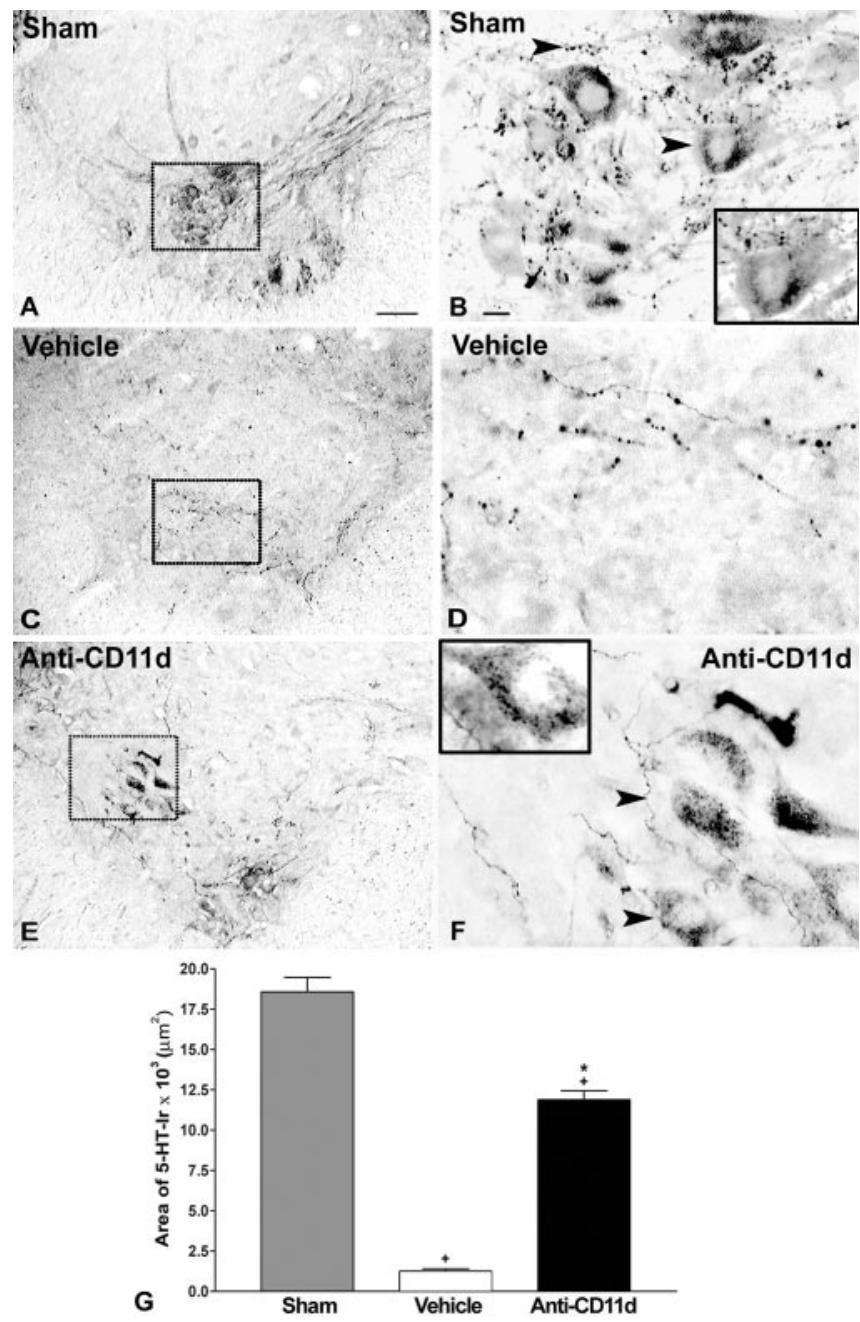

Figure 5. 5-HT-IR in laminas VII-IX of the ventral horn caudal to injury 4 weeks after SCl. $A-F$, Photomicrographs of transverse sections of the ventral horn in sham-injured $(A, B)$, vehicle-treated $(C, D)$, and anti-CD11d mAb-treated $(E, F)$ animals. After $S C l$, the distribution and density of 5-HT-immunoreactive fibers were significantly reduced to sparsely distributed varicose fibers observed in control animals $(C, D)$. Anti-CD11d mAb treatment resulted in increased distribution of 5-HT-IR in fibers and terminal boutons (arrowheads) opposing the somata of $\alpha$-motoneurons $(E, F)$, similar to patterns observed in sham-injured animals $(A, B) . B, G$, Insets, Higher-power photomicrographs of the neuron indicated by an arrow in this field of view. Scale bars: $A, C, E, 100 \mu \mathrm{m} ; B, D, F, 20 \mu \mathrm{m}$. G, The area of 5-HT-IRin the ventral horn caudal to the lesion site represented as the mean area \pm SE of $5-\mathrm{HT}$-IR in the sham-injured $(n=5)$, vehicle-treated $(n=6)$, and anti-CD11d mAb-treated $(n=5)$ groups. ${ }^{*} p<0.05$ compared with vehicle-treated rats; ${ }^{+} p<0.05$ compared with sham-injured rats.

anti-CD11d mAb treatment, an increase in 5-HT-IR within the IML was clearly visible, characterized by varicose fibers projecting toward the central canal and robust labeling of fibers within the IML and lateral funiculus (Fig. 4C). Occasional small round bodies of intense immunoreactivity in the IML may have been parts of densely innervated preganglionic neurons or small interneurons (data not shown). The area of 5-HT-IR in this treated group (5848 $\left.\pm 1373 \mu \mathrm{m}^{2} ; n=6\right)$ was significantly increased when compared with that in both the sham-injured and vehicletreated groups (Fig. 4D) $(p<0.05)$.

Anti-CD11d mAb treatment protects serotonergic fiber distribution in the ventral horn caudal to lesion

As we found in the IML, the distribution and density of 5-HTimmunoreactive fibers around the small number of motor neu- 
rons in the ventral horn rostral to the lesion were not noticeably altered by SCI or anti-CD11d mAb treatment at 4 weeks after SCI (data not shown); therefore, we did not undertake a quantitative analysis of the ventral horn rostral to the injury. In contrast, marked changes in ventral horn 5-HT-IR caudal to SCI were obvious. Accordingly, we investigated the density of 5-HT-IR within laminas VII-IX of the ventral horn in L2-4. In the shaminjured group, numerous 5-HT-immunoreactive fibers were observed throughout laminas VII-IX of the ventral horn, with a dense plexus of varicose fibers located within lamina VIII, projecting from the dorsal commissure (Fig. $5 A, B$ ). Immunoreactive product also appeared within terminal boutons surrounding the somata of motoneurons both medially in lamina IX as well as laterally along the border of laminas VII and VIII, particularly in sham-injured and anti-CD11d mAb-treated animals (Fig. $5 B, F$ ).

The area of the ventral horn 5-HT-IR that was quantified encompassed a majority of lamina VII and all of laminas VIII and IX. The IML and lamina X were excluded. The area of 5-HT-IR in segments L2-4 of sham-injured animals was $18,565 \pm 2019 \mu \mathrm{m}^{2}$ $(n=5)$. Four weeks after injury, beaded varicose fibers immunoreactive for 5-HT were distributed sparsely throughout the ventral horn after vehicle treatment (Fig. $5 C, D$ ). The area of 5-HT-IR in vehicle-treated animals $\left(1255 \pm 363 \mu \mathrm{m}^{2} ; n=6 ; p<0.05\right)$ was significantly smaller than that in sham-injured animals (Fig. 5G). This decrease in 5-HT-immunoreactive fibers after SCI was partially reversed by anti-CD11d mAb treatment. An increased density of varicose fibers, relative to the vehicle-treated group, occurred medially in laminas VIII and IX as well as laterally at the border of laminas VII and VIII (Fig. 5E, F ). 5-HT-immunoreactive terminals apposed the somata of neurons after treatment. Quantification of the areas of 5-HT-immunoreactive fibers revealed a significant, 10-fold increase after mAb treatment $\left(11,882 \pm 1220 \mu \mathrm{m}^{2}\right)$ compared with vehicletreated animals (Fig. $5 G)(n=5 ; p<0.05)$; however, the area of 5-HT-IR after anti-CD11d mAb treatment was still significantly smaller $(64 \%)$ than the area measured in the sham-injured group $(p<0.05)$.

\section{5-HT-immunoreactive fibers caudal to the lesion site appear to originate from spared axons after anti-CD11d mAb treatment}

To visualize and compare more clearly the sprouting of 5-HT fibers within and surrounding the lesion, longitudinal sections encompassing the entire lesion were analyzed. Based on tissue integrity, the rostral and caudal borders of the lesion site were identified easily. Cyst formation within the lesion site was characteristic in both vehicle and anti-CD11d mAb-treated animals (Fig. 6C,D). In vehicle-treated rats, a dense accumulation of tortuous 5-HT-immunoreactive fibers occurred rostral to the lesion site. These fibers did not penetrate through the lesion site border (Fig. 6C). Clusters of 5-HT-immunoreactive fibers coursed along the subpial rim of the cord, on the lateral edge of the lesion site, continuing to the caudal border (Fig. 6E). A few individual 5-HT-immunoreactive fibers were sparsely dispersed within the gray matter in random patterns caudal to the lesion site (Fig. 6G).

After anti-CD11d mAb treatment, descending 5-HTimmunoreactive fibers still accumulated at the rostral border of the lesion site. Similar to the distribution in the vehicle-treated animals, many fibers in the anti-CD11d mAb-treated animals did not penetrate through the lesion border, and a large proportion of these fibers exhibited swollen terminal end bulbs suggestive of retraction of damaged axons (Fig. 6D, box inset); however, clusters of 5-HT-immunoreactive fibers extended along the lateral edge of the cord passing through both the rostral and caudal borders of the lesion site. Adjacent to the rostral part of the lesion, these fiber bundles on the side of the spinal cord appeared thicker in the mAb-treated rats than in the vehicle-treated rats. Caudal to the lesion site, the beaded, 5-HT-immunoreactive fibers continued along one side of the cord, at the subpial rim, and appeared to send collateral branches medially through the white matter, toward the gray-white matter border where a large proportion of 5-HT-immunoreactive fibers were distributed within the IML (Fig. 6F). 5-HT-immunoreactive fibers generally passed along one side of the cord, possibly related to the initial asymmetrical formation of the lesion cavity. The side varied between rats; in Figure 6 the spared bundle in the vehicle-treated rat is on the side opposite that in the mAb-treated rat. Despite a lack of a descending fiber bundle in the opposite subpial rim of anti-CD11 $\mathrm{d} \mathrm{mAb}$ treated animals, a few 5-HT-immunoreactive fibers were present in the gray matter on this side as well (Fig. $6 H$ ). The source of these fibers could not be determined because the fibers could not be associated with ipsilateral white matter bundles or contralateral projections (Fig. $6 \mathrm{H}$ ). The area of 5-HT-immunoreactive fibers in the lesion or in the subpial rim adjacent to the lesion of anti-CD11d mAb-treated rats (Fig. $7 B, C)(n=3$,) was $>10$-fold larger than the areas in vehicle-treated rats (Fig. $7 A, C)(n=4)$. This may be attributed, in part, to thicker bundles coursing along the subpial edge of the rostral part of the lesion.

\section{Compact myelin sparing after SCI was greater after anti-CD11d mAb treatment}

An additional analysis was completed to determine whether the anti-CD11d mAb treatment led to more intact white matter myelin at the lesion site corresponding with the effects on serotonergic axons. Therefore, areas of compact myelin at and near the epicenter of the lesion site were determined (Fig. 8). At 4 weeks after SCI and vehicle treatment, the lesion epicenter at T12-13 was characterized by a large cavitation encompassing the gray and white matter, with barely detectable compact myelin (Fig. $8 \mathrm{~A}$ ). Cavitation spread $2.5 \mathrm{~mm}$ in both the rostral and caudal directions from the epicenter, diminishing with distance. The total cross-sectional areas of the spinal cord at the lesion epicenter in the two groups were not significantly different. In control rats this area was $2.9 \pm 0.7 \mu \mathrm{m}^{2}$, whereas the area in anti-CD11d mAb-treated rats was $3.7 \pm 0.5 \mu \mathrm{m}^{2}$. After anti-CD11d mAb treatment, however, larger areas of compact myelin were present within the lesion epicenter, and enhanced structural integrity was notable throughout the lesion site. After normalizing the area of myelin as a percentage of the total area of the intact cord at $\sim \mathrm{T} 10$, significantly increased areas of compact myelin were observed in the anti-CD11d mAb-treated group in the epicenter and at most levels up to $2.8 \mathrm{~mm}$ rostral and caudal to the epicenter compared with the vehicle-treated group $(n=4 ; p<0.05)$ (Fig. 8). In addition, the white matter/gray matter architecture appeared more normal in both the rostral and caudal directions.

\section{Anti-CD11d mAb treatment does not increase the number of raphe-spinal axons traversing the lesion site}

Retrogradely transported Fluorogold was used to assess the integrity of raphe-spinal axons projecting through the epicenter and caudal to the spinal cord lesion site 4 weeks after the moderate clip-compression injury. Comparisons were made between the neuron counts in the nuclei raphe magnus and raphe pallidus in the anti-CD11d mAb-treated group and the vehicle group (Fig. 9). In many cases, labeled neurons were visible within the reticular formation, specifically the nucleus reticularis gigantocellularis and the 


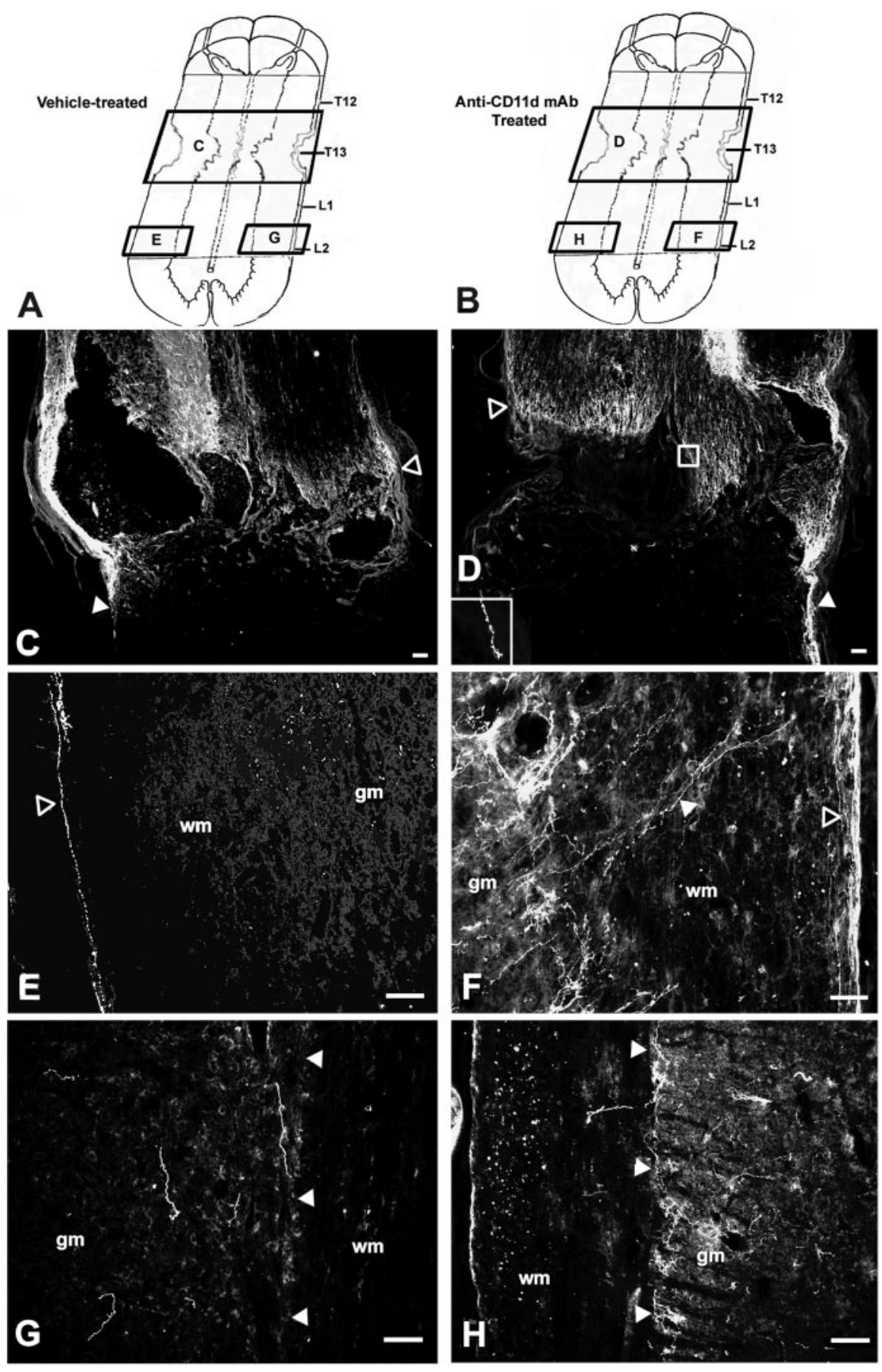

Figure 6. Digital photomicrographs demonstrating the presence of 5 -HT-immunoreactive fibers around and caudal to the T12-L1 lesion in vehicle-treated $(C, E, G)$ and anti-CD11d mAb-treated $(D, F, H)$ animals. Locations of each photomicrograph, with respect to the lesion site, are depicted in $A$ for vehicle-treated and in $B$ for anti-CD11d mAb-treated rats. Longitudinal sections in vehicle-treated animals $(n=5)$ revealed 5 -HT-immunoreactive fibers at the rostral border of the lesion ( $C$, open arrowhead) unable to penetrate into the scar. 5-HT-immunoreactive fibers were observed unilaterally, descending along the subpial rim of the cord $\sim 3.5 \mathrm{~mm}$ caudal to the lesion border ( $E$, open arrowhead). Individual 5 -HT-immunoreactive fibers were distributed sparsely within the gray matter caudal to the lesion in randomized patterns, with no apparent connection to the descending fibers $(G)$. Longitudinal sections in anti-CD11 mAb-treated animals $(n=4)$ revealed 5-HT-IR at the rostral border of the lesion $(D$, open arrowhead), with characteristic axonal retraction ( $D$, inset) unable to permeate the scar. Fibers also extended caudally through the lesion along the subpial rim. Approximately $3.5 \mathrm{~mm}$ caudal to the lesion site, collateral axons extended medially from the subpial rim toward the gray matter border (designated by filled arrowhead) where 5 -HT-immunoreactive fibers accumulated densely within the IML $(F)$. On the contralateral side of the cord, 5 -HT-immunoreactive fibers were present within the IML, in the absence of fiber connections from the contralateral or ipsilateral pial rim $(H) . \mathrm{gm}$, Gray matter; wm, white matter. Scale bars: $C, D, 100 \mu \mathrm{m}$; $E-H, 50 \mu \mathrm{m}$. nucleus reticularis gigantocellularis pars $\alpha$; however, in an attempt to minimize variability, this area was not included in the quantification.

The Fluorogold-labeled neurons in both treatment groups were similar in physical structure and appeared as triangular or oval multipolar cell bodies $\sim 15-30 \mu \mathrm{m}$ in size. Representative photomicrographs of Fluorogold-labeled neurons within the raphe nuclei of salinetreated and anti-CD11d mAb-treated groups are shown in Figure 9, $A$ and $B$, respectively. Many of the Fluorogoldlabeled raphe neurons were immunoreactive for 5-HT (Fig. 9C,D). The number of Fluorogold-labeled neurons was determined using the physical disector method to avoid the possibility of overestimating cell counts. Cell counting revealed no significant difference between the mean number of labeled neurons within the raphe nucleus of the anti-CD11d mAbtreated ( $1294 \pm 960 ; n=6)$ and the salinetreated groups $(658 \pm 667 ; n=5)$. The mAb-treated group had significantly greater variance than the saline-treated group $(p<0.05)$ because of high cell counts in some of the mAb-treated rats. A control group $(n=3)$ was introduced in which the cord was transected at the 12th and 13th thoracic junctions rather than compressed, to ensure that the Fluorogold visualized within the brainstem was caused by retrograde axonal transport and not passive dispersion through the CSF. In all cord-transected animals, Fluorogold was not present within any brainstem neurons (data not shown).

At-level mechanical allodynia is reduced after anti-CD11d mAb treatment

The development of mechanical allodynia immediately rostral and proximal to the injury site was assessed on the dorsal trunk before and 2-4 weeks after SCI. The 15 $\mathrm{mN}$ stimulus was determined to be innocuous in uninjured rats because no responses to the stimulus were made 1 week before injury (Fig. 10A). After SCI, the same stimulus evoked clear avoidance behavior, characterized by escapes and avoidance of the filament, head turns, trunk shakes, vocalization, and aggressive behaviors. At 2 weeks after SCI, injured control rats responded $2.8 \pm 0.9$ times to application of 10 innocuous stimuli to the rostral midthoracic area $(n=8)$ (Fig. $10 A$ ). The number of responses increased over the subsequent 2 weeks until the control group responded $7.9 \pm 0.8$ times at 4 weeks. After anti-CD11d mAb treatment $(n=7)$, animals responded significantly 


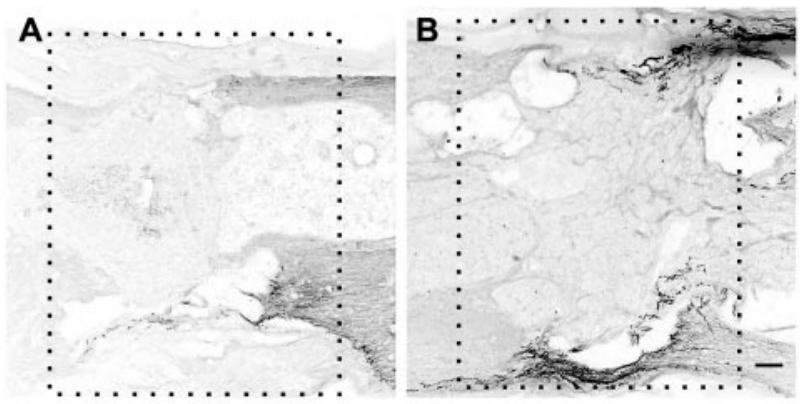

C

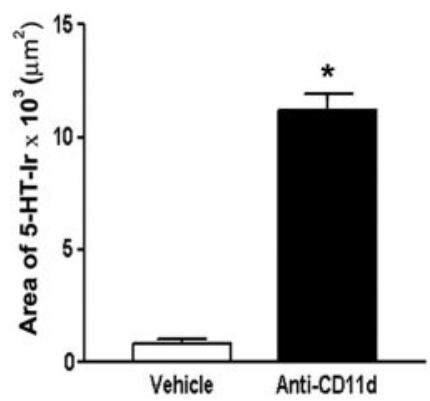

Figure 7. Serotonergic fiber density in and adjacent to the lesion site in vehicle-treated ( $n=$ 4) and anti-CD11d mAb-treated $(n=3)$ rats. Low-power photomicrographs of the lesion areas analyzed in the vehicle- and $\mathrm{mAb}$-treated rats are outlined with boxes in $A$ and $B$, respectively. The rostral side of lesion is on the right of photomicrographs. Images have been reversed to black on white to reveal details of lesion structure. Scale bar, $200 \mu \mathrm{m}$. C, Graph illustrates mean area of immunoreactivity for 5 -HT within the lesion in vehicle- and $\mathrm{mAb}$-treated rats. Data are expressed as mean values \pm SEM. ${ }^{*} p<0.05$ compared with vehicle-treated rats.

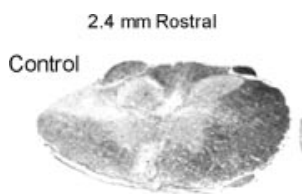

Epicenter

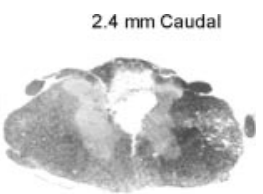

Anti-CD11d
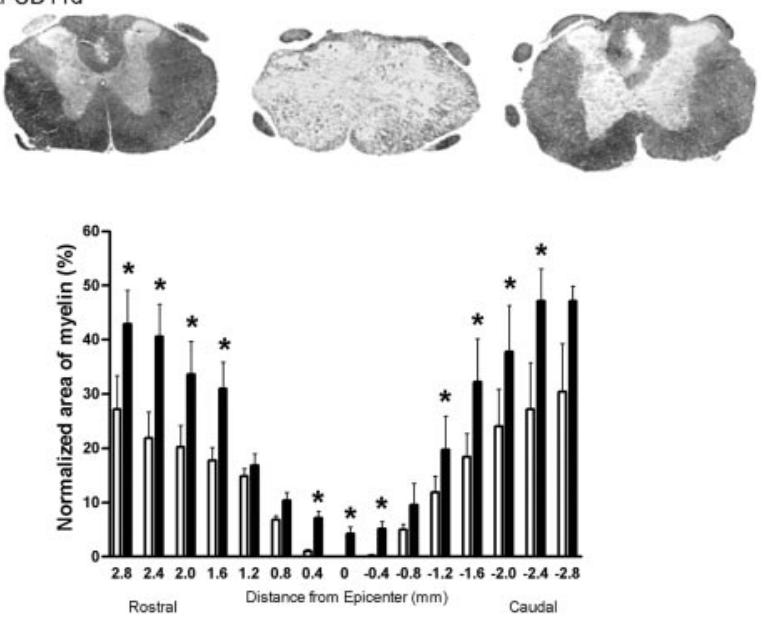

Figure 8. Normalized area of spared myelin stained with Luxol fast blue within the lesion site after SCl. Photomicrographs illustrate compact myelin integrity $2.4 \mathrm{~mm}$ rostral to epicenter, within the epicenter, and $2.4 \mathrm{~mm}$ caudal to epicenter in a vehicle-treated and an anti-CD11dtreated rat. Anti-CD11d-treated animals (filled bars) $(n=4)$ had significantly increased amounts of compact myelin at the epicenter and in most rostral areas compared with vehicletreated animals (open bars) $(n=4) .{ }^{*} p<0.05$ compared with vehicle-treated rats.

less at the 2 week time point $(0.8 \pm 0.4$ avoidance responses $)$ when compared with the vehicle-treated group, as well as significantly less at 3 weeks ( $2.5 \pm 0.7$ avoidance responses $)$ and at 4 weeks (3.5 \pm 0.7 avoidance responses) after SCI $(p<0.05)$.
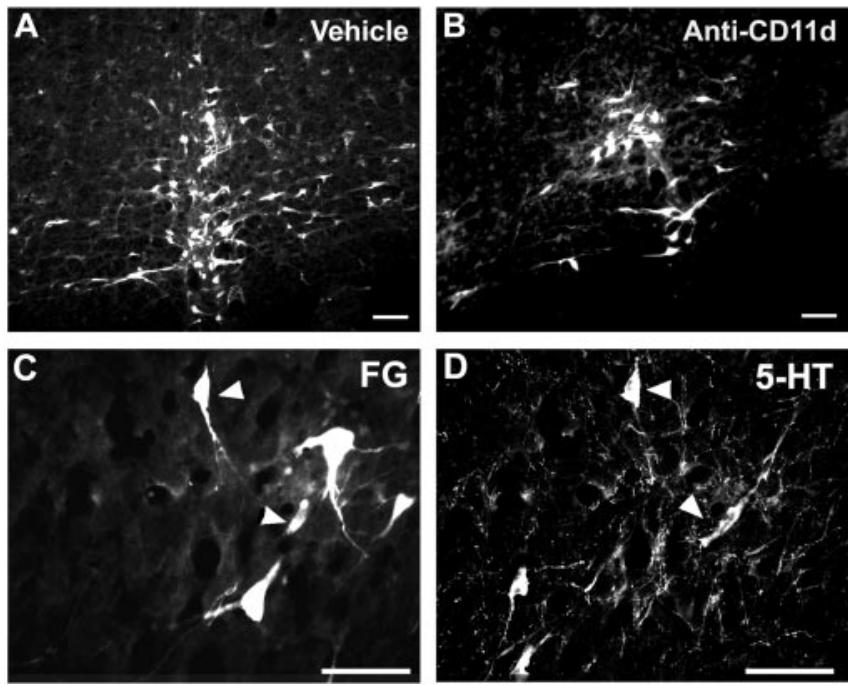

Figure 9. Fluorogold-labeled neurons in the nucleus raphe magnus and nucleus raphe pallidus of vehicle-treated $(n=6)(A)$ and anti-CD11d mAb-treated $(n=5)(B)$ animals. Many of these neurons were immunoreactive for $5-\mathrm{HT}(C, D$, arrowheads indicate double-labeled cells). Scale bars: $A, B, 100 \mu \mathrm{m} ; C, D, 50 \mu \mathrm{m}$.
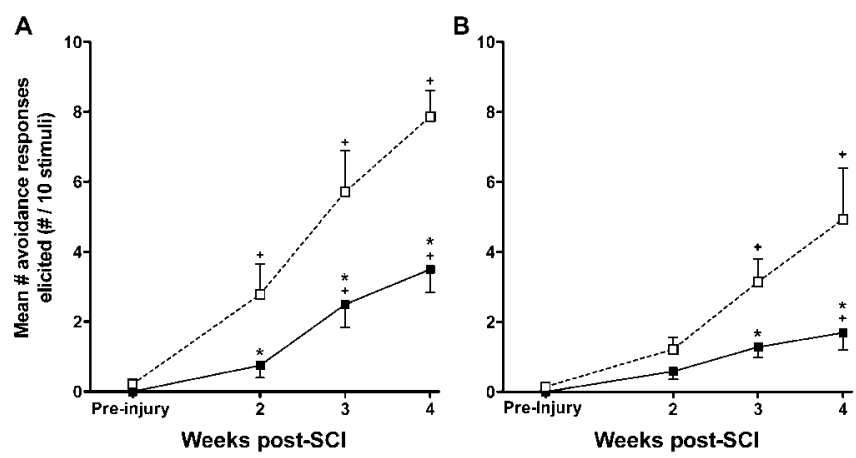

Figure 10. The development of mechanical allodynia at the level $(A)$ and below the level $(B)$ of $\mathrm{SCl}$ lesion site. Testing sessions consisted of 10 stimulations with an innocuous, monofilament stimulus 1 week before injury and at 2, 3, and 4 weeks after injury. Each data point represents the mean \pm SEM number of avoidance responses made to 10 stimulations. $A$, The number of avoidances made in response to dorsal trunk stimulation was significantly reduced after anti-CD11d mAb treatment (filled squares) $(n=7)$ when compared with vehicle-treated animals (open squares) $(n=8)$, suggesting the reduction of at-level mechanical allodynia. $B$, The number of paw withdrawals was also reduced in the anti-CD11d mAb-treated group (filled squares) ( $n=7)$ when compared with the vehicle-treated group (open squares) $(n=8)$, suggesting attenuation of below-level mechanical allodynia. ${ }^{*} p<0.05$ compared with vehicle-treated rats; ${ }^{+} p<0.05$ compared with mean responses before injury.

When compared with baseline measurements before injury, the number of avoidance responses was increased significantly at 2, 3, and 4 weeks in the control group after SCI. In contrast, the number of responses made by the mAb-treated group after SCI was not significantly different from the measurements at 2 weeks after injury but was different at 3 and 4 weeks $(p<0.05)$.

Below-level mechanical allodynia is reduced after anti-CD11d mAb treatment

Because of the probable mechanistic differences underlying the development and maintenance of mechanical allodynia at various segmental cord levels after SCI, changes in below-level mechanical allodynia after anti-CD11d mAb treatment were assessed. These were measured by quantifying the number of withdrawal behaviors made in response to stimulation of the 


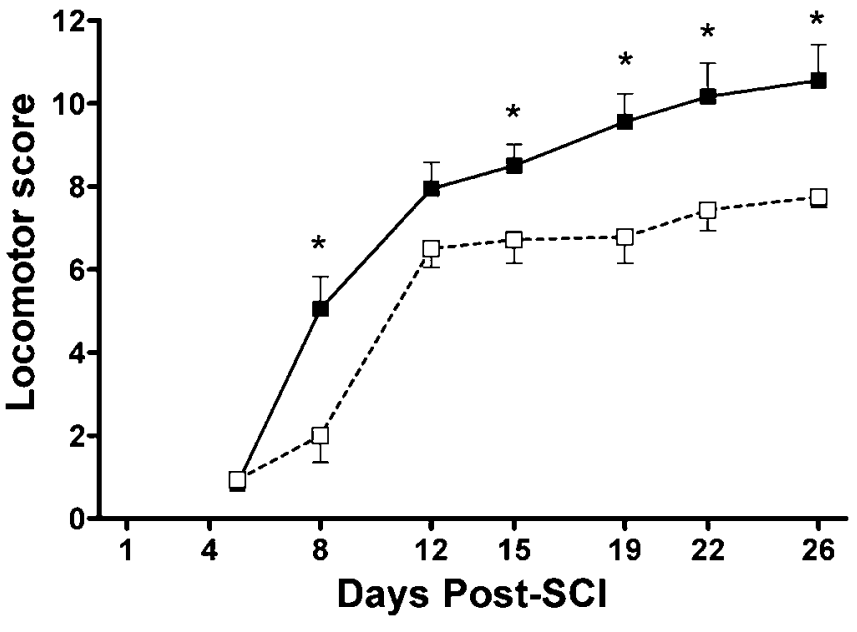

Figure 11. BBB open-field locomotor scores assessed from $5 \mathrm{~d}$ to 4 weeks after SCI. Mean \pm SEM scores were generated as an average of the individual scores from the two hindlimbs. CD11d mAb-treated rats (filled squares) $(n=9)$ had significantly higher locomotor scores at days $8,15,19,22$, and 26 compared with vehicle-treated rats (open squares) $(n=7) .{ }^{*} p<0.05$ compared with vehicle-treated rats.

plantar surface of the hindpaw with the innocuous filament. Again, the stimulus generating a force of $15 \mathrm{mN}$ was determined to be innocuous. Uninjured rats did not respond by withdrawal of the paw before SCI (Fig. $10 \mathrm{~B}$ ). Unlike at-level allodynia testing, treated $(n=7)$ and control $(n=8)$ groups were not significantly different with respect to the number of paw withdrawal responses at 2 weeks after SCI (control, $1.2 \pm 0.3$ vs treated, $0.6 \pm 0.2$ ) (Fig. $10 \mathrm{~B})$. The number of withdrawal responses to the innocuous filament did increase in the control group over the subsequent 2 weeks, suggesting the development of mechanical allodynia. During the third week, control animals made $3.1 \pm 0.7$ withdrawal responses to the 10 stimulations, and by the fourth week, $4.9 \pm 1.5$ withdrawal responses were elicited. In contrast, antiCD11d mAb-treated rats responded significantly less $(p<0.05)$ at the 3 and 4 week time points, making $1.3 \pm 0.3$ withdrawals at 3 weeks and $1.7 \pm 0.5$ withdrawals at 4 weeks. Assessment during the fourth week revealed that four of the eight treated rats were making less than one withdrawal response to the 10 stimulations. When compared with responses before injury, the control group made significantly more withdrawals at 3 and 4 weeks after injury, whereas the number of withdrawals made by treated animals was significantly different only at 4 weeks $(p<0.05)$.

\section{Locomotor performance after SCI is improved by anti-CD11d mAb treatment}

To correlate with the altered density and distribution of spinal 5-HT-IR fibers after anti-CD11d mAb treatment, assessments of functional recovery were performed. Using the 21 point $\mathrm{BBB}$ open-field scale, locomotor recovery after SCI was compared between the treated $(n=9)$ and control $(n=7)$ groups for 4 weeks. At $5 \mathrm{~d}$ after SCI, the hindlimb function of the treated group (BBB score: $0.8 \pm 0.1)$ was the same as that of the control group $(0.9 \pm$ 0.1) (Fig. 11). At $8 \mathrm{~d}$ after SCI, however, the treated group scored an average of $5.1 \pm 0.8$, showing extensive movement in one joint and slight movement in the other two. The control injured group performed significantly worse $(p<0.05)$, scoring an average of $2.0 \pm 0.7$, and showed extensive movement of only one joint. Locomotor scores for the control group reached a plateau at day 12 , whereas the scores for the treated animals increased slightly, even at the 4 week time point. At 4 weeks, treated animals scored an average of $10.6 \pm 0.9$, demonstrating occasional weightsupporting plantar stepping. Some rats within the treated group scored as high as 14, with consistent weight-supporting plantar steps, consistent gait coordination, and rotated paw placement. At the same time, the score of the vehicle-treated group was significantly lower $(7.8 \pm 0.3 ; p<0.05)$; these rats were unable to sweep the hindlimbs. The difference in score between the treated and control groups clearly indicates a functional change: the ability to bear weight was recovered after $\mathrm{mAb}$ treatment, whereas the control group could execute only simple hindlimb extension.

\section{Discussion}

The anti-CD11d integrin strategy reduces the early intraspinal inflammatory cell infiltrate after SCI and, correspondingly, decreases oxidative damage to the spinal cord, sparing gray and white matter and promoting sensory, autonomic, and motor recovery (Bao et al., 2004a,b; Gris et al., 2004; Saville et al., 2004). This study extends our previous findings, demonstrating that this treatment minimizes changes in serotonergic pathways in the spinal cord that are likely to be a substrate for neurological dysfunction after SCI. Sensory, motor, and autonomic disorders resulting from SCI correspond to defined alterations in the density and distribution of 5-HT fibers both rostral and caudal to the lesion site (Bruce et al., 2002; Hains et al., 2002). We now demonstrate that at 4 weeks after SCI, 5-HT-immunoreactive fiber density rostral to the injury was reduced toward normal in $\mathrm{mAb}$ treated rats, and the density of these fibers was increased caudal to the lesion, coinciding with reductions in mechanical allodynia at and below the injury, respectively. The treatment also led to increased 5-HT-immunoreactive fiber density in the IML and ventral horn caudal to injury, changes that could underlie autonomic recovery and corresponded to improved locomotor function. The treatment appeared to improve the collateral sprouting of spared axons caudal to the injury site rather than significantly increasing the number of axons traversing through the lesion. Overall, these results demonstrate that the tissue sparing caused by targeting the early inflammatory cascade after SCI results in a more normal distribution of serotonergic fibers rostral and caudal to the injury, associated with positive functional outcomes.

The role of early inflammation after a primary injury in triggering progressive secondary cell death has been well documented (Bethea and Dietrich, 2002). After injury, the intraspinal trafficking of hematogenous neutrophils and macrophages exacerbates tissue damage via the release of cytokines, proteases, free radicals, and chondroitin sulfate proteoglycans (Fitch and Silver, 1997; Popovich et al., 1997). Extravasation of these inflammatory cells through the blood-CNS barrier is facilitated by the adhesion relationship between the vascular adhesion molecule-1 on the surface of endothelial cells and the CD11d/CD18 integrin localized on leukocytes (Van der Vieren et al., 1999). Our treatment with the anti-CD11d mAb transiently limits this influx only for $72 \mathrm{~h}$; the number of macrophages in the injured cord at $7 \mathrm{~d}$ after SCI is the same in mAb-treated as in control rats (Saville et al., 2004). Accordingly, this treatment was highly selective and transient, permitting the "wound healing" actions of immune cells to commence after an initial period of neuroprotection (Bethea and Dietrich, 2002; Saville et al., 2004).

The increase in serotonergic fiber density rostral to the injury occurred in both the anti-CD11d mAb-treated and vehicletreated groups and was particularly noted in the dorsal horn. Longitudinal sections through the lesion site revealed a robust plexus of 5-HT-immunoreactive fibers immediately rostral to the lesion epicenter with clear axonal dieback. Similarly, Inman and 
Steward (2003) reported a dense accumulation of 5-HTimmunoreactive fibers rostral to the SCI lesion site that were "disorganized and meandering" and unable to extend into the central lesion. They termed this response "aberrant regenerative sprouting," defined as the axonal growth that does not culminate in reconnection of the injured axon with its normal target. The $\mathrm{mAb}$ treatment in our study reduced the sprouting response, perhaps because of gray matter sparing at the lesion borders and increased availability of target neurons for connection (Gris et al., 2004). Whether connections occurred, and if so, whether they were functional, is unknown.

5-HT-immunoreactive fibers were distributed within the dorsal horn, IML, and ventral horn caudal to the lesion after antiCD11d mAb treatment. Serotonergic axons extended along the lateral edge of the lesion through the area corresponding to the rim of compact myelin around the lesion epicenter. In mAbtreated animals, collateral sprouting of fibers from these spared bulbospinal axons into the gray matter appears to be related to enhanced functional recovery. Greater sprouting in the treated rats may be associated with gray and white matter sparing adjacent to the injury noted in this study and previously (Gris et al., 2004). The more intact gray matter in these rats would provide a larger number of denervated neuronal targets, prompting sprouting of axons into areas below the injury site (Polistina et al., 1990). The serotonergic fibers did not appear to originate from spinal interneurons caudal to the injury because none were clearly identified. The only possible region for such a source was the IML, in which the density of 5-HT-IR was particularly intense and small immunoreactive bodies were observed; however, these may have been parts of heavily innervated preganglionic neurons. Instead it seemed that serotonergic fibers caudal to the injury site were directed particularly to the IML and ventral horn. This might have merely reflected the proximity of these areas to the population of spared bundles that traversed the lesion site.

The increases in the density and distribution of 5-HTimmunoreactive fibers within the dorsal horn rostral to the injury occurred in spinal segments corresponding to dermatomes in which at-level mechanical allodynia develops (Bruce et al., 2002). The anti-CD11d mAb treatment had parallel effects, reducing this 5-HT-immunoreactive fiber density and at-level mechanical allodynia. In contrast, the increase in caudal 5-HT-immunoreactive fiber density after anti-CD11d mAb treatment correlated with an attenuation of below-level allodynia. These results are consistent with the biphasic, modulatory nature of spinal 5-HT in the maintenance of neuropathic pain. 5-HT can inhibit (Crisp et al., 1991; Bardin et al., 2000) and facilitate (Ali et al., 1996; Green et al., 2000) spinal pain transmission, a complexity attributable to distinct bulbospinal pathways for descending inhibition and descending facilitation (Zhuo and Gebhart, 1994) and the presence of multiple intraspinal serotonergic receptor subtypes (Lin et al., 1996). The paradoxical development of mechanical allodynia both above and below the lesion may be explained by alterations within the endogenous serotonergic system. Accumulation of 5-HT fibers rostral to injury may contribute to the maintenance of mechanical allodynia via facilitatory actions at the spinal $5-\mathrm{HT}_{3}$ receptors, as we have demonstrated previously (Oatway et al., 2004). Conversely, the loss of 5-HT caudal to injury may result in the loss of the descending inhibition of pain transmission at the high-affinity $5-\mathrm{HT}_{1}$ and $5-\mathrm{HT}_{2}$ receptors (Sawynok and Reid, 1996).

Improved locomotor recovery after anti-CD11d mAb treatment was associated with recovery of 5-HT-IR within the lumbar ventral horn toward normal. This serotonergic input was charac- terized mainly by an increased number of beaded axons with large spherical varicosities in the ventral horn and evidence of terminal boutons apposing $\alpha$-motoneurons, relative to the vehicle-treated group. Initiation of hindlimb movement uses serotonergic activation of motor output via control of central pattern generator circuitry (Rossignol et al., 1988; Jacobs and Fornal, 1997). After transection SCI, transplantation of 5-HT-releasing embryonic raphe cells leads to locomotor improvement (Ribotta et al., 2000). Increased 5-HT fiber density within the lumbar ventral horn, caudal to the lesion site, after anti-CD11d mAb treatment therefore may be directly related to the recovered locomotion via modulated excitatory input to $\alpha$-motoneurons and central pattern generator circuitry.

Similarly, a robust increase in 5-HT-IR was observed in the lumbar IML after anti-CD11d mAb treatment. Without functional assessment, the impact on autonomic function of this increased 5-HT-IR is unknown. Certainly, the loss of 5-HTimmunoreactive fibers within the IML caudal to the lesion site would be detrimental and is most likely related to the loss of autonomic function after injury. Correlations have been drawn between age-associated declines in lumbosacral 5-HT innervation and alterations in micturition and innervation of the urinary tract (Ranson et al., 2003). Increased 5-HT-IR in the lumbar IML after anti-CD11d mAb treatment therefore may have some benefit in the recovery of independent bladder and bowel control after SCI.

Despite increases in serotonergic fibers caudal to the lesion site, the mAb treatment did not increase the number of retrogradely labeled bulbospinal neurons. Treatments that lead to improved functional recovery often are associated with an increased number of retrogradely labeled brainstem neurons (Schumacher et al., 2000; Lu et al., 2002), enhanced white matter sparing, and decreased scar tissue formation (Ma et al., 2001). In this study, the degree of tissue sparing within the lesion epicenter after antiCD11d mAb treatment was $\sim 5 \%$ of the normalized spinal cord area, in comparison with a complete loss in the control rats. This small increase could not have been detected with the retrograde tract tracing method that we used. Although the number of bulbospinal axons traversing the lesion may not differ between antiCD11d mAb-treated and saline-treated animals, the number of sprouting collaterals from these axons certainly was enhanced after anti-CD11d mAb treatment, which may account for enhanced supraspinal connectivity.

In summary, our results demonstrate that improved motor and sensory recovery after an early, anti-inflammatory treatment is associated with a more normal pattern of 5-HT fiber distribution both rostral and caudal to the SCI lesion site and with tissue sparing at and near the lesion epicenter. The complex serotonergic influences on pain and motor function are greatly disrupted by SCI. This relatively simple anti-inflammatory strategy made significant progress in returning these control systems toward normal.

\section{References}

Ainge G, Cook JL, Gisby PT (1969) Rapid staining of myelin in paraffin sections with Luxol fast blue MBS. J Med Lab Technol 26:231-232.

Ali Z, Wu G, Kozlov A, Barasi S (1996) The role of $5 \mathrm{HT}_{3}$ in nociceptive processing in the rat spinal cord: results from behavioural and electrophysiological studies. Neurosci Lett 208:203-207.

Allen GV, Cechetto DF (1994) Serotoninergic and nonserotoninergic neurons in the medullary raphe system have axon collateral projections to autonomic and somatic cell groups in the medulla and spinal cord. J Comp Neurol 350:357-366.

Bao F, Chen Y, Dekaban GA, Weaver LC (2004a) An anti-CD11d integrin 
antibody reduces cyclooxygenase- 2 expression and protein and DNA oxidation after spinal cord injury in rats. J Neurochem 90:1194-1204.

Bao F, Chen Y, Dekaban GA, Weaver LC (2004b) Early anti-inflammatory treatment reduces lipid peroxidation and protein nitration after spinal cord injury in rats. J Neurochem 88:1335-1344.

Bardin L, Schmidt J, Alloui A, Eschalier A (2000) Effect of intrathecal administration of serotonin in chronic pain models in rats. Eur J Pharmacol 409:37-43.

Basso DM, Beattie MS, Bresnahan JC (1995) A sensitive and reliable locomotor rating scale for open field testing in rats. J Neurotrauma 12:1-21.

Bethea JR, Dietrich WD (2002) Targeting the host inflammatory response in traumatic spinal cord injury. Curr Opin Neurol 15:355-360.

Bruce JC, Oatway MA, Weaver LC (2002) Chronic pain after clip compression injury of the rat spinal cord. Exp Neurol 178:33-48.

Calejesan AA, Ch'ang MH, Zhuo M (1998) Spinal serotonergic receptors mediate facilitation of a nociceptive reflex by subcutaneous formalin injection into the hindpaw in rats. Brain Res 798:46-54.

Crisp T, Stafinsky JL, Uram M, Perni VC, Weaver MF, Spanos LJ (1991) Serotonin contributes to the spinal antinociceptive effects of morphine. Pharmacol Biochem Behav 39:591-595.

Fehlings MG, Tator CH (1995) The relationships among the severity of spinal cord injury, residual neurological function, axon counts, and counts of retrogradely labeled neurons after experimental spinal cord injury. Exp Neurol 132:220-228.

Fitch MT, Silver J (1997) Activated macrophages and the blood-brain barrier: inflammation after CNS injury leads to increases in putative inhibitory molecules. Exp Neurol 148:587-603.

Green GM, Scarth J, Dickenson A (2000) An excitatory role for 5-HT in spinal inflammatory nociceptive transmission: state-dependent actions via dorsal horn 5-HT(3) receptors in the anaesthetized rat. Pain 89:81-88.

Gris D, Marsh DR, Oatway MA, Chen Y, Hamilton EF, Dekaban GA, Weaver LC (2004) Transient blockade of the CD11d/CD18 integrin reduces secondary damage after spinal cord injury, improving sensory, autonomic, and motor function. J Neurosci 24:4043-4051.

Gundersen HJ, Bagger P, Bendtsen TF, Evans SM, Korbo L, Marcussen N, Moller A, Nielsen K, Nyengaard JR, Pakkenberg B (1988) The new stereological tools: disector, fractionator, nucleator and point sampled intercepts and their use in pathological research and diagnosis. APMIS 96:857-881.

Hains BC, Everhart AW, Fullwood SD, Hulsebosch CE (2002) Changes in serotonin, serotonin transporter expression and serotonin denervation supersensitivity: involvement in chronic central pain after spinal hemisection in the rat. Exp Neurol 175:347-362.

Hamon M, Bourgoin S (1999) Serotonin and its receptors in pain control. In: Novel aspects of pain management: opioids and beyond (Sawynok J, Cowan A, eds), pp 203-228. New York: Wiley.

Inman DM, Steward O (2003) Ascending sensory, but not other long-tract axons, regenerate into the connective tissue matrix that forms at the site of a spinal cord injury in mice. J Comp Neurol 462:431-449.

Jacobs BL, Fornal CA (1997) Serotonin and motor activity. Curr Opin Neurobiol 7:820-825.

Jacobs BL, Martin-Cora FJ, Fornal CA (2002) Activity of medullary serotonergic neurons in freely moving animals. Brain Res Brain Res Rev 40:45-52.

Joshi M, Fehlings MG (2002) Development and characterization of a novel, graded model of clip compressive spinal cord injury in the mouse: Part 2. Quantitative neuroanatomical assessment and analysis of the relationships between axonal tracts, residual tissue, and locomotor recovery. J Neurotrauma 19:191-203.

Lin Q, Peng YB, Willis WD (1996) Antinociception and inhibition from the periaqueductal gray are mediated in part by spinal 5-hydroxytryptamine $(1 \mathrm{~A})$ receptors. J Pharmacol Exp Ther 276:958-967.

Lu J, Feron F, Mackay-Sim A, Waite PM (2002) Olfactory ensheathing cells promote locomotor recovery after delayed transplantation into transected spinal cord. Brain 125:14-21.

Ma M, Basso DM, Walters P, Stokes BT, Jakeman LB (2001) Behavioral and histological outcomes following graded spinal cord contusion injury in the C57BL/6 mouse. Exp Neurol 169:239-254.

Mabon PJ, Weaver LC, Dekaban GA (2000) Inhibition of monocyte/macrophage migration to a spinal cord injury site by an antibody to the integrin alphaD: a potential new anti-inflammatory treatment. Exp Neurol 166:52-64.

Oatway MA, Chen Y, Weaver LC (2004) The 5-HT3 receptor facilitates atlevel mechanical allodynia following spinal cord injury. Pain 110:259-268.

Paxinos G, Watson C (1986) The rat brain in stereotaxic coordinates. New York: Academic.

Plunkett JA, Yu CG, Easton JM, Bethea JR, Yezierski RP (2001) Effects of interleukin-10 (IL-10) on pain behavior and gene expression following excitotoxic spinal cord injury in the rat. Exp Neurol 168:144-154.

Polistina DC, Murray M, Goldberger ME (1990) Plasticity of dorsal root and descending serotoninergic projections after partial deafferentation of the adult rat spinal cord. J Comp Neurol 299:349-363.

Popovich PG, Wei P, Stokes BT (1997) Cellular inflammatory response after spinal cord injury in Sprague-Dawley and Lewis rats. J Comp Neurol 377:443-464.

Popovich PG, Guan Z, Wei P, Huitinga I, van Rooijen N, Stokes BT (1999) Depletion of hematogenous macrophages promotes partial hindlimb recovery and neuroanatomical repair after experimental spinal cord injury. Exp Neurol 158:351-365.

Ranson RN, Dodds AL, Smith MJ, Santer RM, Watson AH (2003) Ageassociated changes in the monoaminergic innervation of rat lumbosacral spinal cord. Brain Res 972:149-158.

Reid JM, Gwym DG, Flumerfelt BA (1975) A cytoarchitectonic and Golgi study of the red nucleus in the rat. J Comp Neurol 162:337-361.

Ribotta MG, Provencher J, Feraboli-Lohnherr D, Rossignol S, Privat A, Orsal D (2000) Activation of locomotion in adult chronic spinal rats is achieved by transplantation of embryonic raphe cells reinnervating a precise lumbar level. J Neurosci 20:5144-5152.

Rossignol S, Lund JP, Drew T (1988) The role of sensory inputs in regulating patterns of rhythmical movements in higher vertebrates. A comparison between locomotion, respiration, and mastication. In: Neural control of rhythmic movements in vertebrates (Cohen AH, Rossignol S, Grillner S, eds), pp 201-228. New York: Wiley.

Saruhashi Y, Young W, Perkins R (1996) The recovery of 5-HT immunoreactivity in lumbosacral spinal cord and locomotor function after thoracic hemisection. Exp Neurol 139:203-213.

Saville LR, Pospisil CH, Mawhinney LA, Bao F, Simedria FC, Peters AA, O'Connell PJ, Weaver LC, Dekaban GA (2004) A monoclonal antibody to $\mathrm{CD} 11 \mathrm{~d}$ reduces the inflammatory infiltrate into the injured spinal cord: a potential neuroprotective treatment. J Neuroimmunol 156:42-57.

Sawynok J, Reid A (1996) Neurotoxin-induced lesions to central serotonergic, noradrenergic and dopaminergic systems modify caffeine-induced antinociception in the formalin test and locomotor stimulation in rats. J Pharmacol Exp Ther 277:646-653.

Schumacher PA, Siman RG, Fehlings MG (2000) Pretreatment with calpain inhibitor CEP-4143 inhibits calpain I activation and cytoskeletal degradation, improves neurological function, and enhances axonal survival after traumatic spinal cord injury. J Neurochem 74:1646-1655.

Siddall PJ, Loeser JD (2001) Pain following spinal cord injury. Spinal Cord 39:63-73.

Sokol RR, Rohlf FJ (1981) Biometry: the principles and practice of statistics in biological research. San Francisco: Freeman.

Sterio DC (1984) The unbiased estimation of number and sizes of arbitrary particles using the disector. J Microsc 134:127-136.

Tasker RR (1990) Pain resulting from central nervous system pathology (central pain). In: The management of pain (Bonica JJ, ed), pp 264-283. Philadelphia: Lea and Febiger.

Van der Vieren M, Crowe DT, Hoekstra D, Vazeux R, Hoffman PA, Grayson MH, Bochner BS, Gallatin WM, Staunton DE (1999) The leukocyte integrin $\alpha \mathrm{D} \beta 2$ binds VCAM-1: evidence for a binding interface between I domain and VCAM-1. J Immunol 163:1984-1990.

Vierck Jr CJ, Siddall P, Yezierski RP (2000) Pain following spinal cord injury: animal models and mechanistic studies. Pain 89:1-5.

Weaver LC, Verghese P, Bruce JC, Fehlings MG, Krenz NR, Marsh DR (2001) Autonomic dysreflexia and primary afferent sprouting after clipcompression injury of the rat spinal cord. J Neurotrauma 18:1107-1119.

Zhuo M, Gebhart GF (1994) Spinal serotonin receptors mediate descending facilitation of a nociceptive reflex from the nuclei reticularis gigantocellularis and gigantocellularis pars alpha in the rat. Brain Res 550:35-48. 